\title{
On the preparation of hydrobromic and hydriodic acid
}

\section{Mellon}

To cite this article: M. Mellon (1842) On the preparation of hydrobromic and hydriodic acid, Philosophical Magazine Series 3, 20:133, 529-530, DOI: 10.1080/14786444208650628

To link to this article: http://dx.doi.org/10.1080/14786444208650628

曲 Published online: 01 Jun 2009.

Submit your article to this journal ๘

Џ Article views: 2

Q View related articles $\sqsubset$ 


\section{Intelligence and Miscellaneous Articles.}

ON IODINE IN COMMERCIAL NITRJC ACID.

M. LEMBERT observes, that among the substances which render the nitric acid of commerce impure, there is one which has not been hitherto suspected, but which is not unimportant, namely, iodine. The following are the means by which its presence was demonstrated, for the first time, in purifying nitric acid : in order to obtain pure concentrated nitric acid, $M$. Lembert takes the nitric acid of commerce, adds nitrate of silver to it, and allows it to remain for some days; then pours off the clear acid, adds an equal weight of concentrated sulphuric acid, and distils the mixture. On one occasion in concentrating the sulphuric acid remaining in the retort, and when this was nearly completed, violet vapours appeared, and afterwards crystals of iodine were formed in the tube used as a refrigeratory.

Saturate nitric acid containing iodine with potash or soda, and to the solution add a little clear solution of starch, and a few drops of sulphuric acid, taking care not to add it till after it has been proved that the quantity already used was insufficient to effect the coloration. The presence of iodine will be thus determined by the blue or purple colour which the liquid will assume.

Reflecting on the origin of the iodine in the nitric acid, it was natural, says $M$. Lembert, to think that it was derived from the nitrate of soda used in preparing the acid; he consequently examined this salt by adding to a solution of it a small quantity of solution of starch, and then of sulphuric acid, and the colour indicative of the presence of iodine was produced.

M. Lembert remarks, that 1 st, concentrated nitric acid, that is to say, of specific gravity about $1 \cdot 4$, contains iodine, while the weaker acid, or of specific gravity about $1 \cdot 3$, does not: 2 ndly, neither chlorine nor sulphurous acid indicates the presence of iodine either in natural nitrate of soda or the neutralized acid.-Journal de Pharm. et de Chimie, Avril 1842.

\section{ON THE PREPARATION OF HYDKOBROMIC AND HYDRIODIC ACID. BY M. MELLON.}

The author obtains hydrobromic acid by introducing into a flask about 230 grains of bromidé of potassium and a little water; he then adds about 380 grains of bromine and 30 grains of phosphorus in small pieces; he afterwards adapts a conducting tube to the neck of the flask; in a short time reaction commences, and it may become so strong as to render it necessary to immerse the flask in cold water. When the action diminishes, heat is to be gently applied by a spiritlamp; the residue is a mixture of unaltered bromine and phosphate of potash ; the gas liberated is derived from two different sources; it results from the formation of bromide of phosphorus, which water decomposes into hydrobromic and phosphoric acids; and secondly, from the action of the phosphoric acid thus formed on the bromide of potassium.

Prizl. Mag. S. 3. Vol. 20. No.133. June 1842. $2 \mathrm{~N}$ 
The reaction is represented by the following equation :

$2 \mathrm{BrK}+5 \mathrm{Br}+\mathrm{Ph}+6 \mathrm{HO}=\mathrm{PHO}^{5}, \mathrm{KO}+6 \mathrm{BrH}$.

When bromine is replaced by iodine, and the alkaline bromide by the iodide, an abundant and regular disengagement of hydriodic acid is obtained: it is requisite merely to raise the temperature slightly.-Ibid.

QUANTITATIVE DE'TERMINATION OF PHOSPHORIC ACID.

M. Schulze determines the quantity of phosphoric acid in soils, \&c. by a process dependent on the following property: the phosphates of lime and of magnesia are soluble in acetic acid, whilst those of peroxide of iron and alumina are insoluble in it. The addition of a sufficient quantity of a solution of peracetate of iron or of acetate of alumina, completely precipitates the phosphoric acid in combination with peroxide of iron or with alumina, from the phosphate of lime and of magnesia dissolved by acetic acid.

The acid liquor procured by treating soils with hydrochloric acid usually contains a much larger quantity of alnmina and peroxide of iron than corresponds to the quantity of phosphoric acid. Consequently, if after the oxidation of the iron the excess of acid is supersaturated with ammonia, and the peroxide of iron, alumina and compounds of phosphoric acid are thus precipitated, all this acid will remain in an insoluble state, combined with peroxide of iron and alumina, on the subsequent addition of excess of acetic acid and the application of heat; while the rest will dissolve.-Ibid.

\section{NEW MINERALS.-ANDESINE*.}

M. Abich has analysed a mineral from the Andes which was called Pseudo-albite on account of its having been found in twin crystals very similar to albite. Its cleavage, however, is less distinct than albite, and the cleavage planes are more undecided and less angular. This mineral is imbedded in a whitish gray mass called andesite, of sp. gr. 3.5924, mixed with hornblende and quartz; the crystals, when broken out, leave a shining impression. The specific gravity is $3 \cdot 7328$, therefore greater than that of albite. Separates before the blowpipe into thin fragments, and fuses into a porous drossy bead.

Analysed with carbonate of barytes it gave,

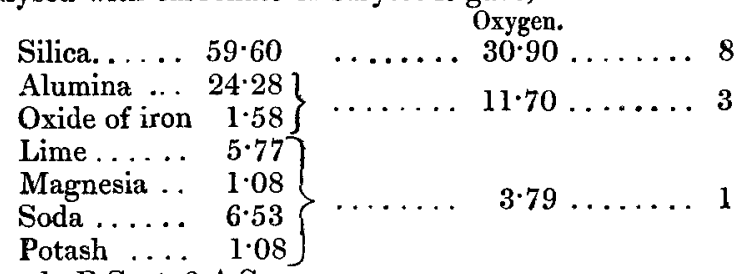

Formula $\mathrm{RS}_{2}+3 \mathrm{AS}_{2}$.

It is therefore a leucite, in which the potash is replaced principally by soda and lime.

* Berzelius, Jahresbericht, and Journal für Praltische Chemie. 